\title{
A framework for the dissemination and utilisation of nutrition research for health promotion and healthcare practice
}

\author{
Yessica Abigail Tronco Hernandez ${ }^{1}$ and Roy Rajshri ${ }^{2}$ \\ ${ }^{1}$ Plymouth University \\ ${ }^{2}$ Discipline of Nutrition and Dietetics Faculty of Medical and Health Sciences, University of \\ Auckland
}

July 15, 2021

\begin{abstract}
Research dissemination has become a significant concern for linking scientific evidence with practice. Universities and research centres are a seedbed for new and emerging research. Research dissemination practices about nutrition and diet must increase through health promotion and education given the concerning global prevalence of diseases related to nutrition and diet. We constructed a research dissemination framework for use in the disciplines of nutrition and dietetics, or other areas with clinical components. The designed framework consists of tools to improve communication of research, links with key departments to increase outreach, and impact measures. This framework provides a tailored, cost-effective and sustainable way to measurably increase the use by research staff of resources to disseminate their findings to key stakeholders in clinical practice and research institutions. This also has the potential to be adopted by academics and researchers so that the end-users such as health professionals, policymakers and public health authorities can be reached. The increased uptake of research outputs can inform health education and promotion strategies that benefit wider society given the concerning global prevalence of diseases related to nutrition and diet. 2
\end{abstract}

\section{Hosted file}

manuscript NZ 071421_YATHwithRR.pdf available at https://authorea.com/users/425772/articles/ 530499-a-framework-for-the-dissemination-and-utilisation-of-nutrition-research-forhealth-promotion-and-healthcare-practice 